\title{
Fibrin degradation products in rheumatoid arthritis
}

\author{
R. M. BENNETT, A. C. EDDIE-QUARTEY, AND P. J. L. HOLT \\ Department of Medicine, Royal Postgraduate Medical School, Hammersmith Hospital, London, W12 OHS
}

The presence of fibrin in the joints, raised levels of blood fibrinogen, and an increased total daily fibrinogen turnover are well-known features of rheumatoid arthritis (Takeda, 1967) and inflammatory arthritis. A possible role for fibrin in the pathogenesis of rheumatoid arthritis, through its action as an autoimmunogen, was suggested by the production of a chronic inflammatory arthritis in rabbits by heterologous and to a lesser degree autologous fibrin injected intra-articularly into previously sensitized animals (Dumonde and Glynn, 1962). An alternative pathogenic mechanism has been attributed to the chemotactic effect of its derivatives and consequent perpetuation of inflammation by neutrophils (Bluhm, Riddle and Barnhart, 1966). In addition there has been a growing appreciation of the role of both local and disseminated intravascular coagulation as an intermediary mechanism in many disease processes (McKay, 1965). Both intravascular fibrinolysis (Andersen and Winther, 1969) and intra-articular fibrinolysis (Barnhart, Riddle and Bluhm, 1967a) have been previously reported in rheumatoid arthritis. This paper reports on the levels of fibrin degradation products (FDPs) in the serum of patients with rheumatoid arthritis, osteoarthrosis, and cutaneous vasculitis, and on synovial fluid levels in patients with rheumatoid and osteoarthrotic effusions.

Fibrin degradation products which are produced by fibrin and fibrinogen proteolysis (Marder, Shulman, and Carroll, 1969) are sensitive indicators of occult fibrinolysis, being detectable before other evidence of consumption of fibrinogen, platelets, or other coagulation factors is obtained (Das, Allen, Woodfield, and Cash, 1967). The technique for the assay of FDPs is based on a haemagglutination inhibition immunoassay (Merskey, Lalezari, and Johnson, 1969) and is sensitive and highly reproducible, having been used in many recently published reports on FDP levels (Naish, Sevitt, Pitney, and Peters, 1970; Ruckley, Das, Leitch, Donaldson, Copland, Redpath, Scott, and Cash, 1970). The method depends on the

Accepted for publication March 2, 1972. fact that high molecular weight derivatives of fibrin and fibrinogen proteolysis share common antigenic determinants with their parent molecules and will thus react with antiserum to fibrinogen (Marder and others, 1969). However, previous treatment of samples with thrombin results in the clotting of all fibrinogen present leaving the uncoagulable FDPs in the supernatant. Thus fibrinogen and FDPs can be separated. These are then assayed by agglutination of human fibrinogen-coated red blood cells by antihuman fibrinogen antiserum, this agglutination being competitively inhibited by free fibrinogen or its degradation products (FDPs) present in the mixture in direct proportion to their concentrations.

\section{Patients and methods}

Sera were studied from a total of 76 persons, comprising sixteen healthy laboratory staff, 55 patients with classical or definite rheumatoid arthritis (Ropes, Bennett, Cobb, Jacox, and Jessar, 1969) forty being seropositive and fifteen seronegative, and five patients with non-rheumatoid vasculitis.

Synovial fluid was obtained from thirteen rheumatoid patients, two patients with traumatic effusions, four with osteoarthrosis, and one with Reiter's syndrome; simultaneous serum samples were taken from nine of these subjects.

Samples for serum FDPS were obtained after 20 to 30 minutes' rest with no smoking allowed, since both exercise and nicotine are known to promote fibrinolysis. $5 \mathrm{ml}$. blood were added to a non-siliconized glass bottle containing $0.5 \mathrm{ml}$. of 10 per cent. $\epsilon$-aminocaproic acid (EACA) (Epsikapron, Kabi Pharmaceuticals Ltd.) to prevent further fibrinolysis. The tubes were centrifuged at 2,000 r.p.m. for $10 \mathrm{~min}$. and the serum was then removed. 100 units of thrombin (Thrombin, Topical, Parke-Davies) were added to the serum which was then incubated for $30 \mathrm{~min}$. at $37^{\circ} \mathrm{C}$.

Synovial fluid was similarly collected into nonsiliconized glass bottles containing $0.5 \mathrm{ml} .10$ per cent. EACA. After the addition of a small amount of hyaluronidase (Hyalase, Fisons) and incubation at $37^{\circ} \mathrm{C}$. for $15 \mathrm{~min}$. in order to reduce the viscosity, 100 units of thrombin 
were added and incubation was continued for another $30 \mathrm{~min}$. The tubes were then centrifuged at 2,000 r.p.m. for $10 \mathrm{~min}$. to remove any residual fibrinogen. All specimens were stored at $-20^{\circ} \mathrm{C}$. before estimation which was performed within 14 days.

Fibrinogen degradation product assays were performed by the haemagglutination inhibition immunoassay method of Merskey and others (1969). Each assay was read by two observers who recorded the result independently. The agglutination end-point was well demarcated and observer differences correspondingly infrequent; when they occurred the assay was repeated. The testing of each new batch of coated cells with standard solutions of fibrinogen and the insistence upon a minimum level of sensitivity ensured that the method gave results of extremely high reproducibility. Rabbit antihuman fibrinogen serum was prepared by immunization with human fibrinogen (Grade A, Kabi Pharmaceuticals Ltd) and its specificity tested by Ouchterlony's double diffusion method.

Batches of specimens were assayed with freshly prepared human group 0 red blood cells and compared with standard solutions of human fibrinogen.

The immunoassay was sensitive enough to demonstrate fibrinogen levels of $0.78 \mu \mathrm{g} . / \mathrm{ml}$., any batches of cells inferior to this level being discarded.

\section{Statistical methods}

The significance of mean values was assessed by finding the standard error of the difference between the two means and comparing this with the observed difference, a significant difference $(\mathrm{P}<0.05)$ being an observed difference of at least twice the standard error. The coefficient of correlation was calculated from the standard regression equation for the observed values. The regression coefficient was considered to be significant if it exceeded twice its own standard error.

\section{Results}

\section{NORMAL SUBJECTS}

FDPs were detected in all the sera from the healthy controls (Fig. 1) the standard deviation being $\pm 3 \cdot 4$.

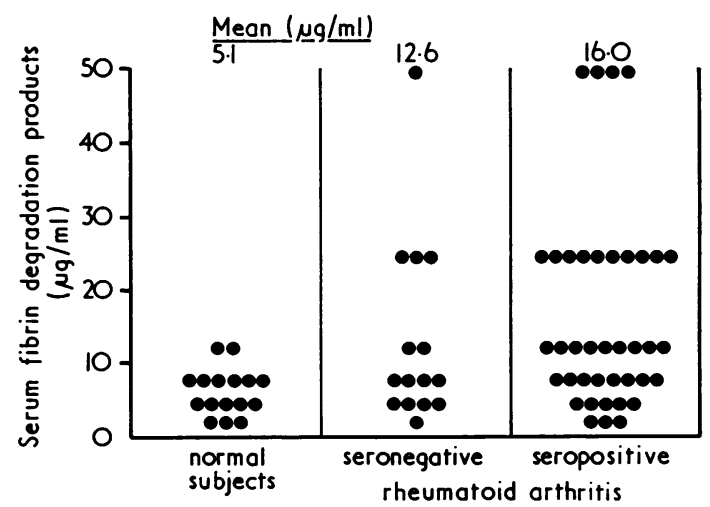

FIG. 1 Serum levels of fibrin degradation products

\section{RHEUMATOID PATIENTS}

These patients had generally increased serum levels of FDPs in comparison with the controls (Fig. 1), the standard deviations being $\pm 13 \cdot 1$ and $\pm 14 \cdot 2$ for the seronegative and seropositive groups respectively. A significant difference was observed between seropositive patients and controls $(0.05>\mathrm{P}>0.01)$ but not between seronegative patients and controls $(0.1>P>0.05)$. Four seropositive patients had FDP levels of $50 \mu \mathrm{g} . / \mathrm{ml}$. and ten had levels of $25 \mu \mathrm{g} . / \mathrm{ml}$. All these patients had active synovitis involving three or more major joints, but none had clinical evidence of vasculitis.

\section{PATIENTS WITH VASCULITIS}

None of these patients had very high levels of FDPs (Table). The mean value was $9.1 \mu \mathrm{g} . / \mathrm{ml}$. which in comparison with the controls is not significantly raised $(0.1>\mathrm{P}>0.05)$.

Table Serum fibrin degradation products in various type of vasculitis

\begin{tabular}{|c|c|}
\hline Types of vasculitis & FDPs $(\mu \mathrm{g} . / \mathrm{ml})$. \\
\hline Rheumatoid arthritis & $\begin{array}{r}12.5 \\
12.5 \\
3 \cdot 1\end{array}$ \\
\hline Systemic lupus erythematosus & $12 \cdot 5$ \\
\hline Polyarteritis nodosa & $6 \cdot 25$ \\
\hline Nodular vasculitis & $\begin{array}{r}12 \cdot 5 \\
1 \cdot 5\end{array}$ \\
\hline Digital gangrene & $12 \cdot 5$ \\
\hline
\end{tabular}

\section{Synovial fluid FDPs}

There was a wide variation in the synovial fluid levels of FDPs in both rheumatoid patients and those with osteoarthrosis and traumatic effusions (Fig. 2, overleaf), the respective standard deviation being \pm 222 and \pm 139 and the difference of the mean values not being significant. One patient with Reiter's disease had a persistent level of $800 \mu \mathrm{g} . / \mathrm{ml}$. on three occasions in the course of 6 weeks.

\section{Disease activity and serum FDP levels}

All patients with very high levels of serum FDPs had active synovitis involving many joints. A comparison of simultaneous serum FDP values and the ESR (Westergren) in 27 rheumatoid patients is shown in Fig. 3 (overleaf).

There was a positive correlation $(y=44.9+0.81 x$; $r=0.33$ ), this correlation coefficient just exceeding 0.05 for $\mathrm{P}$.

Comparison of serum FDPs and synovial fluid FDPs Nine patients had simultaneous estimations of serum FDPs and synovial fluid FDPs. There was no evidence of any correlation in fact $(y=13.4+0.0053 x$; $r=0 \cdot 017$ ). 


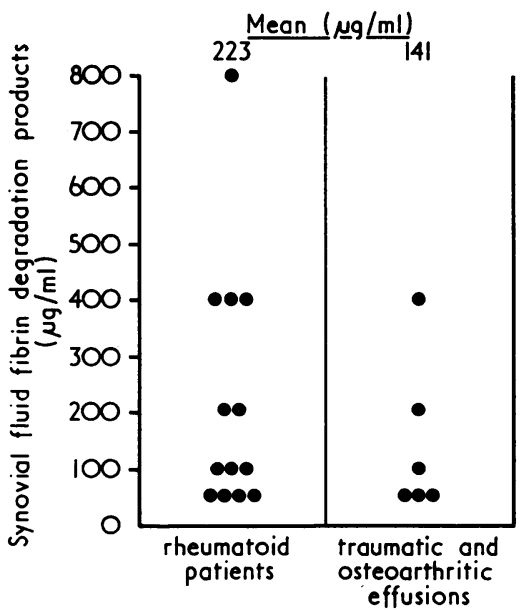

FIG. 2 Synovial fluid levels of fibrin degradation products

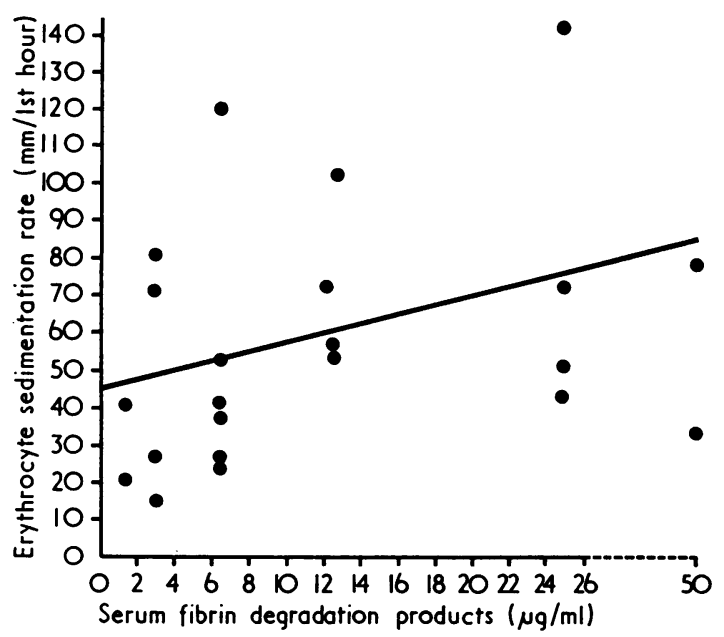

FIG. 3 Relationship of fibrin degradation products to erythrocyte sedimentation rate

\section{Discussion}

In 98 per cent. of a large series of healthy volunteers, Das and others (1967) found detectable levels of serum FDPs using a haemagglutination inhibition method based on tanned sheep red blood cells coated with fibrinogen. Our results on healthy volunteers gave a mean serum value of $5.1 \mu \mathrm{g} . / \mathrm{ml} .(\mathrm{SD} \pm 3.4)$ which closely agrees with that of Das and others, $4.9 \mu \mathrm{g} . / \mathrm{ml}$. $(\mathrm{SD} \pm 2 \cdot 8)$, and demonstrates the reliability and reproducibility of this particular method of measuring FDPs.

Two previous papers have suggested that patients with rheumatoid arthritis have raised levels of serum FDPs: in the study of Thomas, Niewiarowski, Myers, Bloch, and Colman (1970) several patients with rheumatoid arthritis were found to have elevated levels of FDPs, and in a study of FDPs in patients with systemic lupus erythematosus, Kanyerezi, Lwanga, and Bloch (1971) found that nine out of thirteen rheumatoid patients had elevated titres of FDPs. Our work on a larger series of patients confirms these findings and gives figures for FDPs levels, instead of titres as in the previous studies, which permits direct comparison with the results of other workers.

The presence of FDPs in synovial fluid was demonstrated by Barnhart, Riddle, Bluhm, and Quintana (1967b) by an immunological assay employing a turbidometric method. Like us they found considerable variations in both types of traumatic effusion, osteoarthrotic and rheumatoid, although their actual figures $(1.7 \mathrm{mg} . / \mathrm{ml} . \pm 1.4$ for rheumatoid arthritis patients) are considerably higher with a wider deviation than our findings, a reflection, no doubt, of the relative inaccuracy of the turbidometric assay. In a more recent paper, Gormsen, Anderson, and Fedderson (1971) demonstrated FDPs in the synovial fluid of rheumatoid patients showing some of them complexed with fibrin monomers. These bound fibrin monomers are neutralized and thus unable to form a fibrin network, and furthermore the anticoagulant effect of the bound FDPs is decreased (Kowalski, 1968).

Despite the unequivocal evidence of circulating FDPs in healthy people and of raised levels in some diseases, their origin is not yet known. It has been suggested that they result from continuous intravascular coagulation in dynamic equilibrium with fibrinolysis (Das and others, 1967) and that the elevated levels found in disease or produced by anxiety or smoking are the result of increased disseminated coagulation in the microcirculation. If this was the case one would expect to find significantly increased serum levels of FDPs in patients with active vasculitis. Our results in such patients showed no increase and do not support this hypothesis.

A recent suggestion of Kanyerezi and others (1971) is that the raised serum levels of FDPs in rheumatoid arthritis may be derived by diffusion of FDPs from affected joints. However, our results do not show the correlation between serum FDPs and synovial fluid FDPs which would support such a hypothesis. Furthermore, recent work in rats (Van Stone and Khoury, 1971) has shown that extravascular effusions rich in FDPs have no influence upon serum levels of FDPs and that the FDPs in such effusions are taken up by polymorphonuclear leucocytes and thus do not gain access to the general circulation.

The studies of Takeda (1967) and more recently of Andersen and Friis (1971) have shown the fractional catabolic rate of fibrinogen in rheumatoid arthritis to be similar to that in healthy controls. However, as the plasma fibrinogen is invariably elevated in rheumatoid arthritis, there is an increase in the total 
daily fibrinogen turnover, presumably the result of an increased synthesis. Takeda also showed a close correlation between fibrinogen synthesis and the erythrocyte sedimentation rate. Our findings of a positive correlation of the ESR with the serum FDPs therefore suggest that any elevation of serum FDPs is related either to the increased synthesis of fibrinogen or to its increased plasma concentration. We therefore propose a third hypothesis to account for the elevated levels of serum FDPs in rheumatoid arthritis, namely that they are derived from an increased intravascular fibrinogen proteolysis attempting to maintain a dynamic equilibrium with increased fibrinogen synthesis. The proof of this hypothesis awaits the development of techniques which will distinguish between FDPs derived from fibrin proteolysis and those derived from fibrinogen proteolysis.

The study of Andersen and Winther (1969) deserves particular mention as these workers found diminished blood fibrinolysis in patients with rheumatoid arthritis and furthermore that fibrinolysis was inversely related to disease activity, results which are in direct conflict with our findings. However, they estimated blood fibrinolytic activity by the dilute blood clot lysis time and the euglobulin lysis time. Both these tests for fibrinolysis are closely correlated with the serum level of alpha-2 globulin and this fraction of the plasma proteins contains a specific plasmin inhibitor, as they themselves point out. As rheumatoid disease activity is usually associated with a rise in the alpha-2 globulin fraction their results are predictable and consistent. However, raised FDPs, being an end-product, represent incontrovertible evidence of increased fibrinolysis, whereas the dilute blood clot lysis time and the euglobulin lysis time are more specifically related to the plasmin inhibitor/activator ratio and the plasmin activator concentration respectively. As Das and others (1967) have pointed out, although there was a positive correlation between FDPs and the euglobulin lysis time, the relation was not highly significant.

The high levels of FDPs in synovial fluids presumably reflect the rapid degradation of fibrin when it gains access to the joint cavity (Harrold, 1961), for fibrinogen is not normally present in human synovial fluid (Ropes and Bauer, 1935). In this respect the high levels in our patient with Reiter's disease and in patients with gout and other inflammatory arthritides (Barnhart and others, 1967b) is of special significance, and these conditions are not usually accompanied by a persistence of fibrin as is found in rheumatoid arthritis. One infers that, despite high levels of synovial fluid FDPs in rheumatoid arthritis, the intraarticular fibrinolytic system is not able to deal with the deposition of fibrin and an altered homeostasis favouring fibrin persistence develops. One possible reason for this is the finding of low plasminogen activator activity and a high fibrin stabilizing activity in the synovial membrane of patients with rheumatoid arthritis (Andersen and Gormsen, 1970).

\section{Summary}

Serum and synovial fluid levels of fibrin degradation products (FDP) have been measured in patients with rheumatoid arthritis, osteoarthrosis, traumatic effusions, and active cutaneous vasculitis. There was a significant elevation in the serum FDP levels of seropositive rheumatoid patients compared to normals. Synovial fluid levels were greatly in excess of the serum levels in both rheumatoid and non-rheumatoid effusions. High levels of serum FDPs were not related to active vasculitis or high synovial fluid values. A positive correlation was observed between FDP levels and the erythrocyte sedimentation rate.

This work was supported in part by a grant from The Arthritis and Rheumatism Council for Research.

\section{References}

ANDersen, R. BACH, AND Fris, T. (1971) Acta rheum. scand., 17, 94 (Metabolism of fibrinogen in patients with rheumatoid arthritis and in a control group)

- AND GoRMSEN, J. (1970) Ann. rheum. Dis., 29, 287 (Fibrinolytic and fibrin stabilising activity of synovial membranes)

— AND WINTHER, O. (1969) Acta rheum. scand., 15, 178 (Blood fibrinolysis and activity of rheumatoid arthritis)

Barnhart, M. I., Riddle, J. M., AND Bluhm, G. B. (1967a) Ann. rheum. Dis., 26, 281 (Immunocytology in arthritic joints)

$-,-\longrightarrow,-$, AND QuINTANA, C. (1967b) Ibid., 26, 206 (Fibrin promotion and lysis in arthritic joints)

Bluhm, G. B., Riddle, J. M., ANd Barnhart, M. I. (1966) Henry Ford Hosp. med. Bull., 14 , 118 (Significance of fibrin and other particulates in rheumatoid joint inflammation)

Das, P. C., Allen, A. G. E., Woodfield, G. D., ANd Cash, J. D. (1967) Brit. med. J., 4, 718 (Fibrin degradation products in sera of normal subjects)

Dumonde, D. C., AND Glynn, L. E. (1962) Brit.J. exp. Path., 43, 373 (The production of arthritis in rabbits by an immunological reaction to fibrin)

Gormsen, J., Andersen, R. B., ANd Feddersen, C. (1971) Arthr. and Rheum., 14, 503 (Fibrinogen-fibrin breakdown products in pathologic synovial fluids) 
Harrold, A. J. (1961) J. clin. Path., 14, 305 (The defect of blood coagulation in joints)

Kanyerezi, B. R., LWANGa, S. K., AND Bloch, K. J. (1971) Arthr. and Rheum. 14, 267 (Fibrinogen degradation products in serum and urine of patients with systemic lupus erythematosus)

KowALSKI, E. (1968) Seminars in Hematology, 5, No. 1

Marder, V. J., and Carroll, W. R. Shulman, N. R., (1969) J. biol. Chem., 244, 2111 (High molecular weight derivatives of human fibrinogen produced by plasmin)

MCKAY, D. G. (1965) 'Disseminated Intravascular Coagulation'. Harper and Row, New York

Merskey, C., Lalezari, P., And Johnson, A. J. (1969) Proc. Soc. exp. Biol. (N.Y.), 131, 871 (A rapid, simple, sensitive method for measuring fibrinolytic split products in human serum)

Naish, P. F., Sevitt, L. H., Pitney, W. R., AND Peters, D. K. (1970) Clin. Sci., 39, 15P (Fibrinogen derivatives in renal disease)

Ropes, M. W., AND Bauer, W. (1953) 'Synovial Fluid changes in Joint Diseases', p. 52. Harvard Press, Cambridge, Mass.

—, Bennett, G. A., Cobb, S., Jacox, R., and Jessar, R. A. (1959) Ann. rheum. Dis., 18, 49 (Diagnostic criteria for rheumatoid arthritis; 1958 revision)

Ruckley, C. V., Das, P. C., Leitch, A. G., Donaldson, A. A., Copland, W. A., Redpath, A. T., Scott, P., AND CASH, J. D. (1970) Brit. med.J., 4, 395 (Serum fibrin/fibrinogen degradation products associated with postoperative pulmonary embolus and venous thrombosis)

TAKEDA, Y. (1969) J. Lab. clin. Med., 69, 624 (Studies of the metabolism and distribution of fibrinogen in patients with rheumatoid arthritis)

Thomas, D. P., Niewiarowski, S. Myers, A. R., Bloch, K. J., and Colman, R. W. (1970) New Engl. J. Med., 283, 663 (A comparative study of four methods for detecting fibrin degradation products in patients with various diseases)

VAn Stone, J. C., AND Khoury, N. K. (1971) Thromb. Diath. Haemorrh., 25, 142 (The effect of intravascular and extravascular coagulation on serum fibrin degradation products in rats) 